[Chem. Pharm. Bull.

35(12)4915-4920(1987)

\title{
Evaluation of in Vitro and in Situ Transdermal Absorption of Drugs in Pig and Rat Skin
}

\author{
JAN Př́́BORSKÝ, ${ }^{*, a, b}$ Kozo TAKAYAma, ${ }^{a}$ TSUNEJI NAGAi, ${ }^{a}$ \\ DANUŠE WAITZOVÁ, ${ }^{b}$ and JiŘí Elis ${ }^{b}$ \\ Faculty of Pharmaceutical Sciences, Hoshi University, ${ }^{a}$ Ebara-2-4-41, Shinagawa-ku, \\ Tokyo 142, Japan and State Institute for Drug Control, ${ }^{b}$ Srobarova 48, \\ CS 10041 Praha 10, Vinohrady, Czechoslovakia
}

(Received May 18, 1987)

\begin{abstract}
The permeability characteristics of newborn pig skin and adult rat skin, either fresh or stored, to model drugs were examined and compared. Special attention was paid to the design to a new experimental system suitable for evaluation of skin permeability to various substances. Two types of model substances were used; insulin, a poorly absorbable substance with high molecular weight as a representative of peptide drugs, and brilliant blue, a low-molecular, relatively well absorbable substance. In vitro experiments performed with both substances in pig and rat gave comparable values of skin permeability. Maximum insulin concentration in the receiver solution was very similar in all experiments $\left(164.5-180.5 \mu \mathrm{U} / \mathrm{ml} / 24 \mathrm{~h}\right.$ when Azone ${ }^{\circledR}$ was used and $136.5-178.0 \mu \mathrm{U} /$ $\mathrm{ml} / 24 \mathrm{~h}$ when $N$-methyl-2-pyrrolidone (NMP) was used as a penetration enhancer). The donor side concentration of insulin was $2.5 \mathrm{mg} / \mathrm{ml}$.

The optimum concentrations of vehicle and penetration enhancer were $40.0 \%$ propylene glycol (PG) and $0.1 \%$ Azone $^{\circledR}$ or $12.0 \%$ NMP, respectively. Brilliant blue experiments performed with the three skin preparations with $40.0 \% \mathrm{PG}$ and $12.0 \% \mathrm{NMP}$ gave similar values of the flux $J_{\mathrm{T}}$ and permeability $P$ of $1.38-1.97 \mu \mathrm{g} / \mathrm{cm}^{2} / \mathrm{h}$ and $1.56 \times 10^{-5}-2.22 \times 10^{-5} \mathrm{~cm} / \mathrm{h}$, respectively. The concentration of brilliant blue in the donor compartment was $50 \mathrm{mg} / \mathrm{ml}$. There were differences between the lag time in pig and rat skin experiments: about $3 \mathrm{~h}$ in the case of rat skin but $15 \mathrm{~min}$ in pig skin. In comparison to in vitro experiments, in situ studies gave much lower penetration of both test substances expressed as concentration in the receiver compartment. In the case of insulin with Azone ${ }^{\circledR}$ or NMP in the formulation, 30 times or 17 times lower concentration was found, and in brilliant blue experiments almost 5 times lower levels were observed. This new experimental system should be useful for examination of potential drug candidates as well as drug formulations for transdermal use.
\end{abstract}

Keywords_— penetration enhancer; propylene glycol; insulin; brilliant blue; flux; permeability; lag time

Many papers have been published on in vitro transdermal absorption. ${ }^{1-3)}$ Various modifications of the Franz-type permeation cell have usually been used. ${ }^{4-6)}$ Such experiments usually take more than $24 \mathrm{~h},{ }^{7,8)}$ and the skin used is generally fresh or has been stored in a freezer. ${ }^{9-11)}$ In both cases, the skin is dead and some of its biological properties may be altered. Even so, it is assumed that the properties of the skin will remain unchanged throughout the experimental period (at least $24 \mathrm{~h}$ ) in the permeation cell, which is usually in a bath at $37^{\circ} \mathrm{C}$. Under such conditions, where the skin is acting as a kind of membrane, the skin permeability can not be evaluated correctly. Nevertheless, such experiments are still of great importance for evaluation of the relative potency of new penetration enhancers, suitable drug selection and optimum formulation for transdermal absorption.

The aim of the present study was to compare the permeability characteristics of newborn pig skin and rat skin, either fresh or stored, with two model substances. A new experimental system was developed in which in situ full thickness skin is used throughout the experimental 
period to maintain constant conditions.

\section{Experimental}

Materials-Bovine insulin used in this study was purchased from Sigma Chemical Company. Its specific activity was $23.5 \mathrm{U} / \mathrm{mg}$. Azone ${ }^{\circledR}$ was kindly provided by Teijin Co., Ltd. Propylene glycol (PG) was purchased from Wako Pure Chemical Industries, Ltd., and $N$-methyl-2-pyrrolidone (NMP) and Brilliant blue FCF were from Tokyo Kasei Kogyo Co., Ltd. Other chemicals were of a standard analytical grade.

Formulations - Insulin $(2.5 \mathrm{mg} / \mathrm{ml})$ was dissolved in sodium citrate buffer $(\mathrm{pH} \mathrm{3.0)}$, then formulated into solutions containing either Azone ${ }^{\circledR}$ at concentrations from 0.0 to $0.5 \%$ or NMP from 0.0 to $20.0 \%$ (both previously dissolved in $40 \% \mathrm{PG}$ ). Brilliant blue was used as a $50.0 \mathrm{mg} / \mathrm{ml}$ solution formulated in $40.0 \% \mathrm{PG}$ and $12.0 \% \mathrm{NMP}$. The same formulations were used in in situ experiments.

In Vitro Procedure - For in vitro experiments, newborn male pig skin (Landrace female $\times$ Yorkshire male, $F_{1}$ ) from animals weighing $1020 \pm 157 \mathrm{~g}$, and skin of adult Wistar rats $(185.0 \pm 12 \mathrm{~g})$ were used. The skin was taken from the abdominal region. The rats were shaved $24 \mathrm{~h}$ before the experiment and the next day the skin was taken. The skin was used either immediately or after storage for $30 \mathrm{~d}$ at $-20^{\circ} \mathrm{C}$. It was mounted into Franz-type permeation cells ${ }^{5)}$ in which the volume of the receiver compartment was $15 \mathrm{ml}$. Saline was used as a medium in this compartment. The concentrations of drugs applied on the donor side were described above. The temperature of the bath was $37^{\circ} \mathrm{C}$, and the available surface area for penetration was $1.77 \mathrm{~cm}^{2}$. Insulin samples were taken after 10 and $24 \mathrm{~h}$ and brilliant blue samples after $6,12,20$ and $26 \mathrm{~h}$. In the experiments comparing in vitro and in situ procedures, sampling was done after $10 \mathrm{~h}$.

Animal Experiments — These experiments were performed on adult male Wistar rats $(185.0 \pm 10 \mathrm{~g})$. The skin of these animals was prepared the same way as for in vitro experiments but the next day a transverse incision of approximately $3 \mathrm{~cm}$ was made in the lower abdominal region and an acrylate reservoir containing $3.0 \mathrm{ml}$ of saline was applied under the skin, which was first separated from the subcutaneous tissue as well as major blood vessels, so that minor vessels and the capillary network remained. Residual vessels were slightly compressed after application of the acrylic reservoir and cover so that a limited blood supply persisted. The experiment was carried out under sterile conditions. The animals were kept throughout under pentobarbital anesthesia $(0.5 \mathrm{ml} / \mathrm{kg} \mathrm{Nembutal}$ injection, Abbott, containing $50.0 \mathrm{mg} / \mathrm{ml}$ of sodium pentobarbital). The formulations to be studied were applied on the concave portion of the skin surface whose visceral part was pressed into the acrylate reservoir (Fig. 1). To keep the solution on a limited area of skin surface $\left(1.77 \mathrm{~cm}^{2}\right)$, a plastic ring with the same diameter as in the in vitro experiments was used. Samples were taken after $10 \mathrm{~h}$.

Analytical Procedure - Insulin concentrations were measured by using the ELISA method (Insulin B-Test, purchased from Wako Pure Chemical Industries, Ltd.). Brilliant blue was estimated after centrifugation of the sample, by measuring the absorbance at $630 \mathrm{~nm}$ with a Hitachi 124 spectrophotometer. The calibration for brilliant blue was linear over the whole range of measured values.

\section{Results}

We compared newborn pig skin and fresh and stored rat skin using optimum concentrations of all substances in formulations according to our previous results. ${ }^{12)}$ Insulin was used as a peptide drug with low permeation ability. Brilliant blue experiments were used for counting fluxes and other characteristics of skin permeation of the two species. For prediction of differences between in vitro and in vivo experiments, a. new method was introduced.

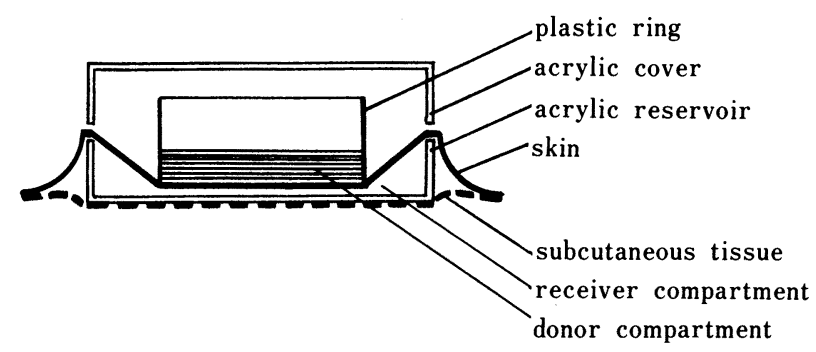

Fig. 1. Device for in Situ Transdermal Application of Drugs 


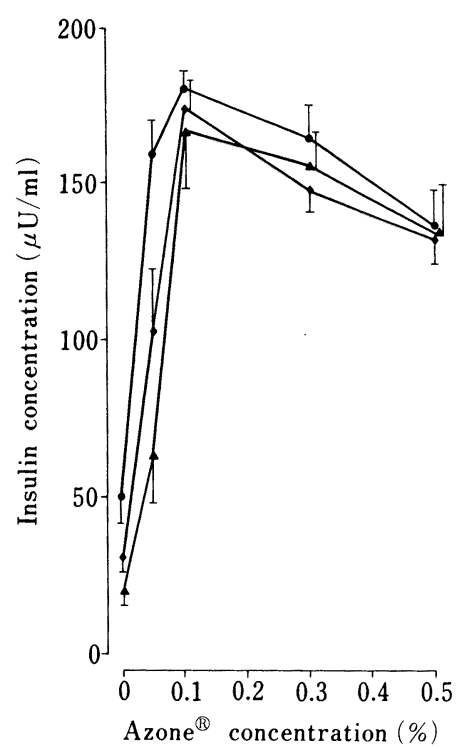

Fig. 2. Effect of Azone ${ }^{\circledR}$ on in Vitro Transdermal Absorption of Insulin

$(\Delta)$ Pig skin, (๑) fresh and $(\bullet)$ stored rat skin Dose $2.5 \mathrm{mg} / \mathrm{ml}$. PG concentration $40 \%$. Sampling time 24 h. Means \pm S.E. $(n=5-6)$.

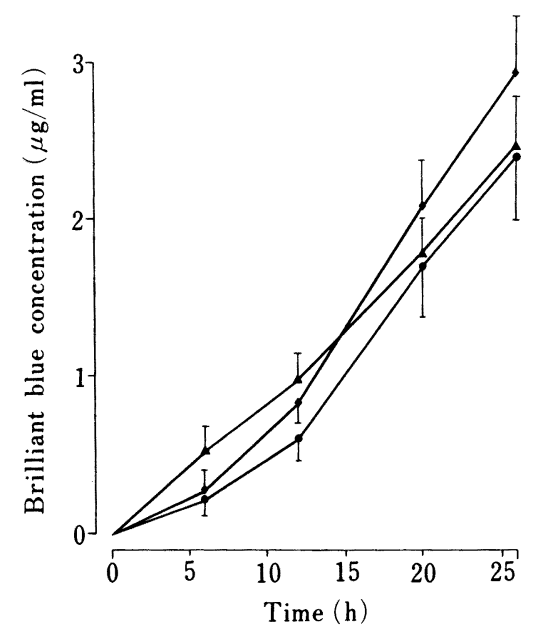

Fig. 4. Effect of NMP on in Vitro Transdermal Absorption of Brilliant Blue

$(\Delta)$ Pig skin, (๑) fresh and $(\diamond)$ stored rat skin Dose $50 \mathrm{mg} / \mathrm{ml}$. NMP concentration $12 \%$. PG concentration $40 \%$. Means \pm S.E. $(n=6)$.

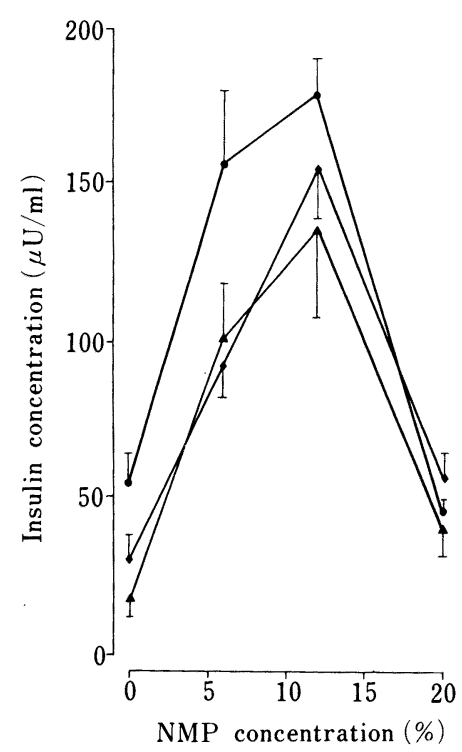

Fig. 3. Effect of NMP on in Vitro Transdermal Absorption of Insulin

$(\boldsymbol{\Delta})$ Pig skin, (๑) fresh and $(\bullet)$ stored rat skin. Dose $2.5 \mathrm{mg} / \mathrm{ml}$. PG concentration $40 \%$. Sampling time 24 h. Means \pm S.E. $(n=5-6)$.

TABle I. Comparison of Lag Time, Flux and Permeability to Brilliant Blue in Newborn Pig Skin, Fresh (f) Rat Skin and after $30 \mathrm{~d}$ Storage (s)

\begin{tabular}{lccc}
\hline \hline & $\begin{array}{c}\text { Lag time }\left(t_{\mathrm{L}}\right) \\
(\mathrm{h})\end{array}$ & $\begin{array}{c}\text { Flux }\left(J_{\mathrm{T}}\right) \\
\left(\mu \mathrm{g} / \mathrm{cm}^{2} / \mathrm{h}\right)\end{array}$ & $\begin{array}{c}\text { Permeability }(P) \\
(\mathrm{cm} / \mathrm{h})\end{array}$ \\
\hline Pig & $0.25^{a)}$ & 1.38 & $1.56 \times 10^{-5}$ \\
Rat $_{\mathrm{f}}$ & 2.85 & 1.53 & $1.73 \times 10^{-5}$ \\
Rat $_{\mathrm{s}}$ & 3.41 & 1.97 & $2.22 \times 10^{-5}$ \\
\hline
\end{tabular}

a) $p<0.01$ ( $v s$. both rat experiments).

Figures 2 and 3 show insulin concentrations in the receiver compartment measured after $24 \mathrm{~h}$ in vitro, with Azone ${ }^{\circledR}$ and NMP was used as penetration enhancers, respectively. The curve shape is characteristic for each enhancer, and there were no significant differences in maximum concentrations of insulin between newborn pig skin and rat skin, either fresh or stored. It seems that the skin of both species has very similar permeation characteristics. 

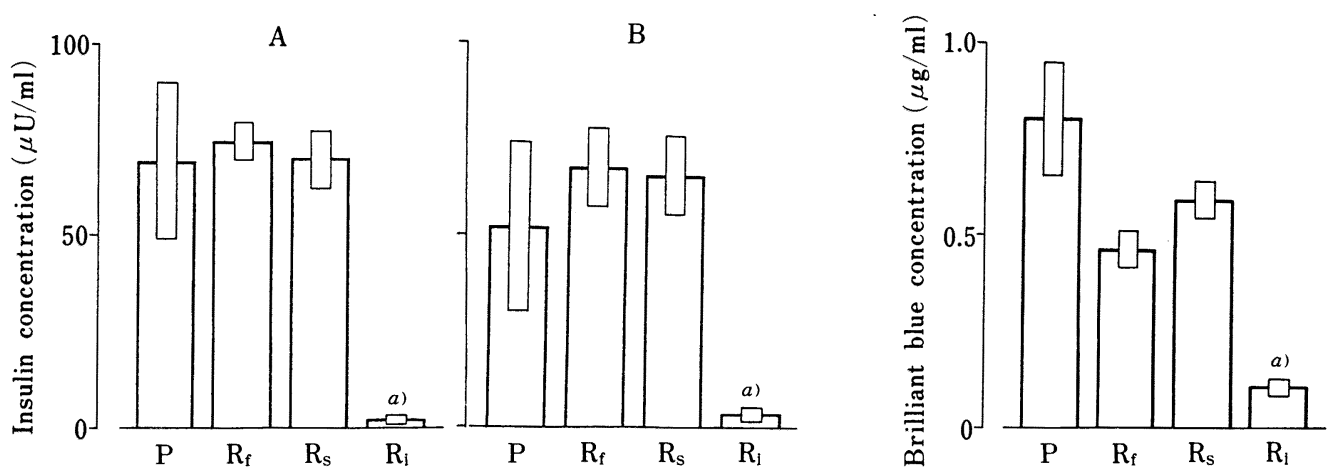

Fig. 5. Comparison of in Vitro and in Situ Transdermal Absorption of Insulin

Fig. 6. Comparison of in Vitro and in Situ $\mathrm{A}=$ Azone $^{\circledR}(0.1 \%), \mathrm{B}=\mathrm{NMP}(12 \%)$ as a penetration enhancer. PG concentration $40 \%$. Sampling time $10 \mathrm{~h} . \mathrm{P}=$ pig, $\mathrm{R}_{\mathrm{f}, \mathrm{s}, \mathrm{i}}=$ rat-fresh, stored, in situ. Means \pm S.E. $(n=5-6)$. The permeated amount is significantly lower in in situ experiments than in in vitro systems (a) $p<0.01)$.

Transdermal Absorption of Brilliant Blue

NMP $(12 \%)$ was used as a penetration enhancer. PG concentration $40 \%$. Sampling time $10 \mathrm{~h} . \mathrm{P}=\mathrm{pig}$, $\mathrm{R}_{\mathrm{f}, \mathrm{s}, \mathrm{i}}=$ rat-fresh, stored, in situ. Means \pm S.E. $(n=$ $5-6)$. The permeated amount was significantly lower in in situ experiments than in in vitro systems $(a)$ $p<0.01)$.

(Maximum concentration of insulin in Azone ${ }^{\circledR}$ experiments was $164.5 \pm 24.1 \mu \mathrm{U} / \mathrm{ml} / 24 \mathrm{~h}$ in pig skin, while the levels were $180.5 \pm 9.9 \mu \mathrm{U} / \mathrm{ml} / 24 \mathrm{~h}$ in fresh rat skin and $172.4 \pm 15.3 \mu \mathrm{U} / \mathrm{ml} / 24 \mathrm{~h}$ in the stored rat skin. In NMP experiments, the maxima were $136.5 \pm 45.7 \mu \mathrm{U} / \mathrm{ml} / 24 \mathrm{~h}$ in pig skin, $178.0 \pm 18.5 \mu \mathrm{U} / \mathrm{ml} / 24 \mathrm{~h}$ in fresh rat skin and $155.3 \pm 33.5 \mu \mathrm{U} / \mathrm{ml} / 24 \mathrm{~h}$ in stored rat skin.) The donor side concentration of insulin was $2.5 \mathrm{mg} / \mathrm{ml}$.

Further examinations carried out with brilliant blue (Fig. 4) confirmed the similarity of both types of the skin and also $30 \mathrm{~d}$ stored skin. The sampling was done after 6, 12, 20 and $26 \mathrm{~h}$ and indicated an almost linear increase of brilliant blue concentration in the receiver compartment during a $26 \mathrm{~h}$ experiment. In all three cases correlation coefficients were very high $\left(r_{\mathrm{xy}}\right.$ was 0.999 in pig skin and 0.994 and 0.997 in rat skin experiments, respectively) and the slopes were similar. These correlation coefficients were calculated between 6 and $26 \mathrm{~h}$, and demonstrate the linearity of the concentration increase. Table I summarizes the parameters of skin permeability. The only marked difference seems to be the duration of the lag time, which was approximately $15 \mathrm{~min}$ with pig skin, but about $3 \mathrm{~h}$ with both fresh and stored rat skin. Values of fluxes and permeabilities were approximately the same in all three cases.

There is usually a great difference between the results obtained in vitro and in vivo. This led us to develop the in situ method described above. The aim was on the one hand to eliminate some of the variables of in vivo experiments such as distribution, metabolism and elimination, and on the other hand to keep the skin alive throughout the experimental period. The skin in in vitro experiments may not maintain its properties during the experiment lasting $24 \mathrm{~h}$ or more in a bath at $37^{\circ} \mathrm{C}$. After completion of the in situ experiments carried out under sterile conditions, the animals were observed for two weeks. The healing of the wound occurred normally and we did not find any macroscopic signs of skin damage. The results of in vitro and in situ experiments with insulin after $10 \mathrm{~h}$ are compared in Fig. 5. Only the formulations containing the optimum concentration of Azone ${ }^{\circledR}(0.1 \%)$ or NMP $(12 \%)$ selected based on the in vitro results were used. The difference between amount of permeated insulin in vitro and in situ for formulations containing Azone ${ }^{\circledR}$ or NMP was about 30 or 17 times, respectively. Brilliant blue also gave a lower permeability in the in situ skin experiment. The difference in amount of permeated brilliant blue was about 5 times (Fig. 6). 


\section{Discussion}

Comparison of skin permeability in various species presents many problems. There is still no effective experimental system for predicting the suitability of a drug and its formulations for transdermal use in human skin. Differences or similarities in skin permeability between various species have been reported, ${ }^{13)}$ and also great differences in permeability in one species measured in various regions of the body. ${ }^{14-16)}$ Our comparison of two species (newborn pig and adult rat skin) indicated similar permeation ability. Of course such a result does not mean that pig and rat skin are similar. The influence of aging is another source of differences, ${ }^{9,17)}$ but the data are also controversial. The skin is most permeable in newborns and young individuals, while aging leads to a decrease in permeability. This led us to use newborn pig skin with relatively high permeability. The results proved that this type of skin is comparable with adult rat skin from the viewpoint of the permeability to insulin as well as to brilliant blue. The only difference in the brilliant blue experiments is in duration of the lag time which was more than 10 times longer in the rat skin than in the newborn pig skin. To exclude regional differences in permeability in one species (which may be in the range of two orders of magnitude $\left.{ }^{15}\right)$ we used only abdominal skin.

Another problem of in vitro experiments is that they are usually carried out for $24 \mathrm{~h}$ or more at $37^{\circ} \mathrm{C}^{7)}$ The skin is actually dead, and of course its properties may change and damage may occur. This could result in a higher permeability of the skin in in vitro systems, while under the same conditions in the in situ model the permeability is very low. In our model we use similar conditions to those used in permeation cells to obtain comparable results. This experimental system may be useful to examine potential drug formulation candidates, since several variables such as distribution, metabolism and elimination are excluded.

The most important part of the method is the preparation of the dermal part and removal of the major blood vessels to prevent drainage of the permeated substance. Small vessels that are not removed are slightly compressed when the acrylic reservoir and cover are applied. The capillary network is not affected and limited blood supply remains. By taking parallel samples from the systemic circulation and from the reservoir we showed that significant leakage into the blood-stream did not occur. As compared with the control group, we did not find any differences in blood concentrations of insulin. In the case of brilliant blue too, no differences between control and experimental animals were observed. To keep the sample on a restricted absorption surface $\left(1.77 \mathrm{~cm}^{2}\right)$, it is necessary to attach a plastic ring on the skin surface.

Based on our experiments we can draw the following conclusions.

1. Newborn pig skin and the skin of adult rats have similar permeation characteristics. The data obtained in our experiments should have value as a basis for further studies of the relationships between experimental systems used for prediction of transdermal permeability.

2. The in situ experimental system should be useful for evaluation of potential drug and formulation candidates for transdermal application. The advantage is that the skin retains the properties of the living tissue throughout the experiment.

Acknowledgements and Technology.

This research was supported by a Special Research Grant from the Ministry of Science

\section{References}

1) D. Mirejovsky and H. Takruri, J. Pharm. Sci., 75, 1089 (1986).

2) Y. Morimoto, K. Sugibayashi, K. Hosoya and W. I. Higuchi, Int. J. Pharm., 32, 31 (1986).

3) E. Touitou, Int. J. Pharm., 33, 37 (1986).

4) T. J. Franz, J. Invest. Dermatol., 64, 190 (1975).

5) E. W. Merritt and E. R. Cooper, J. Controlled Release, 1, 161 (1984). 
6) K. Tojo, M. Ghannam, Y. Sun and Y. W. Chien, J. Controlled Release, 1, 197 (1985).

7) E. R. Cooper and B. Berner, "Methods in Skin Research," John Wiley \& Sons, Ltd., 1985, pp. 407-432.

8) A. Hoelgaard and B. Mollgaard, "Advances in Drug Delivery Systems," Elsevier, Amsterdam, Oxford, New York, Tokyo, 1986, pp. 111-120.

9) R. L. Bronaugh, R. F. Stewart and M. Simon, J. Pharm. Sci., 75, 1094 (1986).

10) T. Ogiso, Y. Ito, M. Iwaki and H. Atago, J. Pharmacobio-Dyn., 9, 517 (1986).

11) K. Sugibayashi, K. Hosoya, Y. Morimoto and W. I. Higuchi, J. Pharm. Pharmacol., 37, 578 (1985).

12) J. Priborsky, K. Takayama, T. Nagai, D. Waitzova and J. Elis, Abstract of Papers, 107th Annual Meeting of the Pharmaceutical Society of Japan, Kyoto, April 1987, p. 842.

13) M. J. Bartek, J. A. La Budde and H. I. Maibach, J. Invest. Dermatol., 58, 114 (1972).

14) J. Hadgraft, Int. J. Pharm., 16, 255 (1983).

15) W. Schalla and H. Schaefer, "Dermal and Transdermal Absorption," W. V. G., Stuttgart, 1982, p. 56.

16) D. Dupuis, A. Rougier, C. Lotte, D. R. Wilson and H. I. Maibach, J. Soc. Cosmet. Chem., 37, 351 (1986).

17) R. H. Guy, Therapeutic Research, 3, 1031 (1985). 